\title{
The Knowledge Body of Requirement Engineering in IST Innovations: An Ontological Analysis
}

\author{
Jonathan Vásquez ${ }^{1^{*}}$, Ariel La Paz
}

\begin{abstract}
Requirement Engineering is considered a key factor for Information Systems and Technology (IST) success in innovation. After roughly 40 years, important questions about the impact of RE in innovations remains. Literature review and bibliometric reports are well-known techniques for describing the state of the art; however, both can cover what has been done, but fail to identify the less developed areas. An alternative method is used to describe the whole knowledge body of RE (KBoRE) for IST innovations, and then systematically identify the most, less and uncovered areas. This paper proposes an Ontological framework of the KBoRE for IST innovations, by decomposing it through the identification of taxonomies and concepts that represent the field. Then, we apply the ontology to map articles from SCOPUS and WoS databases. Results reveal emphases that help to design research agendas and feed the KBoRE for IST Innovations to fill the gaps between the academic curiosity and the industry progress.
\end{abstract}

Keywords: Requirement Engineering; Ontological Analysis; Digital Transformation; Innovation; Information System

Submitted: March 30 $30^{\text {th }}, 2019 /$ Approved: November $8^{\text {th }}, 2019$

\section{Introduction}

Requirements Engineering (RE), is a discipline focused on the elicitation, analysis, negotiation, documentation, validation, and verification of software requirements, and is considered a key factor for the success of Information System and Technology projects (IST) (Cheng \& Atlee, 2007; Daneva, Damian, Marchetto, \& Pastor, 2014). A proper execution of RE might identify and prioritize the stakeholders' needs, improve value communication, reduce misunderstandings between developers and users, help to manage the scope of projects, facilitate testing with business rules and seize the efforts necessary to develop IST, and overall, increase the probability of project success (Cheng \& Atlee, 2007; Nuseibeh \& Easterbrook, 2000; Parnas, 1999). Such an ambitious list of objectives expands as the use and pervasiveness of IST also reach almost all corners of society (Ruhe et al 2017) implying an increasing variety of users and purposes.

The growing interest in the academic community is evidenced in the growing number of scientific publications. A bibliometric description shows that between the end of the 1980s and the year 2017, the number of publications indexed by the Web of Science increased from 3 per year to more than 350 annually; similar trend is observed analyzing the citations to the published research, where for the year 2017 it was computed in more than 8,000 citations. Furthermore, the establishment of important conferences - such as RE, REFSQ, and EmpiRE- and scientific journals focused on RE, such as the Requirements Engineering Journal, demonstrates an ongoing maturity process in the discipline. This development has produced a number of tools, methods, and approaches such as Volere (Robertson \& Robertson, 2000), EARS, and UML-based tools, some of them are still in use and others have been replaced by novel and more effective solutions. Such variety is huge and dynamic as new instruments are being created, implemented, and tested periodically (Moira, 2016).
Nowadays, every organization is immersed in the changes of their environment, such us the full digitalization of companies, requiring complete redesign of their products, services, business processes, and other areas in the organization that is considered as Digital Transformation. These changes are affecting companies and they must properly react to the new directions imposed by factors that make their surroundings more dynamic, complex, and competitive. Organizations need to foresee the coming transformations, either by internal or external factors or detect them in case they missed them and then boost a new manner to do business (Porter, 1998). This 'new manner' can be considered as the 'innovation' phenomenon, and according to literature, it has been widely studied from different research approaches (Edquist, 1996; Geldes, Felzensztein, \& Palacios-Fenech, 2017; Heredia Pérez, Geldes, Kunc, \& Flores, 2019; Pyka, 2002), methods and classifications in order to understand it (Gunday, Ulusoy, Kilic, \& Alpkan, 2011; Oke, 2007; Subramanian \& Nilakanta, 1996). Some definitions in business contexts label innovations as 'business process reengineering" (Hammer \& Champy, 2009), 'revolutionary change' (Ramaprasad, 1982), 'disruptive change' (Christensen \& Overdorf, 2000), or 'creative destruction' (Schumpeter, 1942), and the IST development is at the same time affected and an influencer of this phenomena, by the initiatives of the stakeholders that seek to satisfy their business needs with the aid of IST solutions such as digital transformations, process automation and digitalization. In this context, the $\mathrm{RE}$ might contribute to the innovation process success, functioning as a bridge between the stakeholders' needs and the final information systems products and services.

In spite of the increasing variety of instruments for RE, the rate of success of IST projects is low and the research gap on the impact of $\mathrm{RE}$ for IST innovation is large, considering the importance of the RE in the development of information systems and technologies (Baculard, Colombani, Flam, Lancry \& Spaulding, 2017; Remes, Manyika,

*Corresponding author: jonathan.vasquez@uv.cl

1) Ingeniería en Información y Control de Gestión, Escuela de Auditoría, Universidad de Valparaíso, Valparaíso, Chile

2) Departamento de Control de Gestión y Sistemas de Información, Universidad de Chile, Santiago, Chile 
Bughin, Woetzel, Mischke, \& Krishnan, 2018; Walker, 2017). After roughly 40 years of progress in RE research, important questions remain unsolved about the state of the discipline and where it should further develop to impact the practice in IST, especially in the context of digital transformations and disruptive change (Yin and Pfahl 2017; Cleland-Huang 2018). This article presents an alternative method to: (1) systemically describe the whole Knowledge Body of RE for IST innovations, (2) systematically identify the emphases and gaps in RE to revise and strategically propose research agendas that enhance the use of RE methods, tools and techniques in revolutionary IST projects. The method applied in this study - an ontological analysis decomposed the KBoRE for IST innovations as a composition of taxonomies based on the RE body of knowledge. Then, the ontological framework is used to systematically map all the articles with the titles, abstracts, and keywords about RE and innovation in IST queried from SCOPUS and WoS databases, allowing us to identify the bright and blind/blank documented knowledge for the development of RE in IST innovations.

\section{Related Works}

The development of a discipline is a complex and diffuse process, without guidelines or agenda. In this context, the literature review (LR) seeks to systematize the description of this process. Without a clear image of the discipline, one face the risk of observing only a part of the whole, which would consequently generate a biased lens to address the entire problem systemically (Ramaprasad \& Syn, 2015). LR of RE have analyzed the main trends in the discipline but fail in detecting themes with lesser development or needed by industries leaving important questions unanswered regarding the fit and selection of RE tools and methods for an appropriate specification in the digital innovations and revolution scene brought by the IST innovations.

An analysis of the literature in RE illustrates the growth of the discipline and describes the current emphases. For example, Nuseibeh and Easterbrook (2000) systematically reviewed the publications between 1990 and 2000 to describe the maturity reached in RE as one that allowed the development of workshops and academic meetings by the end of the ' 90 decade; also, the authors identify the need for the creation of new RE techniques. Later, Cheng \& Atlee (Cheng $\&$ Atlee, 2007) updated the literature review of (Nuseibeh \& Easterbrook, 2000), identifying the creation of new tools and the need for strengthening the researcher-practitioner relationship. More recently, Matyokurehwa, Mavetera and Jokonya (2010) considered a time window from 2000 to 2016 for a literature review, evidencing a great variety of methods and techniques, however, none of the these consider the whole RE process systemically and holistically, leaving for the practitioner the task to choose tools for RE implementation from a wide and dynamic variety in the software market. It should be noted that, given the recent but dynamic, rapid and complex growth of RE, researchers have focused their studies in certain aspects, such as the use of techniques in agile development methodologies (Zamudio, Aguilar, Tripp, \& Misra, 2017) or the use of empirical RE techniques (Ambreen, Ikram, Usman, \& Niazi, 2018) either by their importance or urgency, or as a herd effect of what is being published in academic journals.
In the literature, it is found that just a few scholars have done research about RE and IST innovations. For example, Kauppinen, Savolainen, \& Mannisto (2007) observed RE activities in six Finnish companies and identified the vital role that RE plays in the innovative process of an IST development. According to their analysis, three main opportunities arise for RE in innovation: 1) discovering hidden customer and user needs, 2) inventing new product features that satisfy these needs, and 3) supporting feature development with an innovative technical solution. More recently, Munir, Wnuk, \& Runeson (2016) published a systematic review of Open Innovation (OI) in software engineering, where one of their three search string strategies included the 'requirement*' and 'engineer*' keywords. The analysis of the sample showed that OI provided access to a wide and heterogeneous sample of stakeholders, claiming for the use of techniques that allow the identification of the key groups of stakeholders and their understanding; hence, the call for methods that may better satisfy this need.

In the context of missing systemic guidelines, a methodology that makes visible the whole and permits the systematic identification of the main emphases already documented in the literature, as well as its gaps, is considered as an attractive alternative. The ontological frameworks allow the identification and description of the whole, giving way to the systematic mapping of the literature (Ramaprasad \& Syn, 2015). The ontology allows, first, to identify all the parts of Body of Knowledge of Requirement Engineering (KBoRE) for IST innovations, and second, the visualization of the areas that have been widely documented (bright areas of knowledge) and those that have been so far reduced or ignored (blind/blank areas of knowledge). The versatility of the ontological analyses is demonstrated by its use in various disciplines and areas, such as information systems (La Paz, Merigó, Powell, Ramaprasad, \& Syn, 2019) (Manzano, Ramaprasad, \& Syn, 2018), e-commerce (La Paz, Ramaprasad, Syn, \& Vasquez, 2015), healthcare management (Núñez, Neriz, Mateo, Ramis, \& Ramaprasad, 2018; Ramaprasad \& Syn, 2015; Ramaprasad, Win, Syn, Beydoun, \& Dawson, 2016) , culture (Yaco \& Ramaprasad, 2018), education (La Paz \& Arrúa, 2019) (Coronado, La Paz, Ramaprasad, \& Syn, 2015) and sustainable growth (Cancino, La Paz, Ramaprasad, \& Syn, 2018).

\section{Building and Validating the KBoRE for IST Innovations Ontology}

\section{Building the Ontology}

Ontologies focus on the nature and structure of things, independent of any other consideration and even independent from their real existence (Guarino, Oberle, \& Staab, 2009; Ramaprasad \& Syn, 2015). We built an ontology to represent and analyze the KBoRE for ISTi by deconstructing the complexity of the discipline considering two sub-ontologies that represent the Requirement Management and the Innovation Process. The KBoRE for ISTi Ontology is represented by an ordered combination of these sub-ontologies, composed themselves by representative and well-known concepts in RE and innovation processes presented in taxonomies. The final taxonomies and elements grouped in the RE subontology were defined after the analysis of articles in the literature, and in the case of the innovation process sub-ontology, the Global Innovation Index (GII) framework was considered. 
After a comprehensive analysis of literature and the GII framework, we defined the next two sub-ontologies and elements. The sub-ontology of Requirements Management is composed by two taxonomies: (1) Stage and (2) Technique, and the Innovation Process sub-ontology includes: (1) Activity and (2) Innovation Degree. The Figure 1 introduces the KBoRE for IST innovations Ontology, which contains a total of 405 themes/areas of the RE in Digital Transformation contexts, calculated as all the possible combinations of the elements from taxonomies. To illustrate one use of the ontology, two themes have been colored in the figure, and presented here as texts: (1) Requirement analysis tool to describe the modification of IST/IST Projects, and (2) Requirement elicitation method to model the disruption of IST/IST Projects.

Figure 1. KBoRE for ISTiKB Ontology composed by the two ordered sub-ontologies.

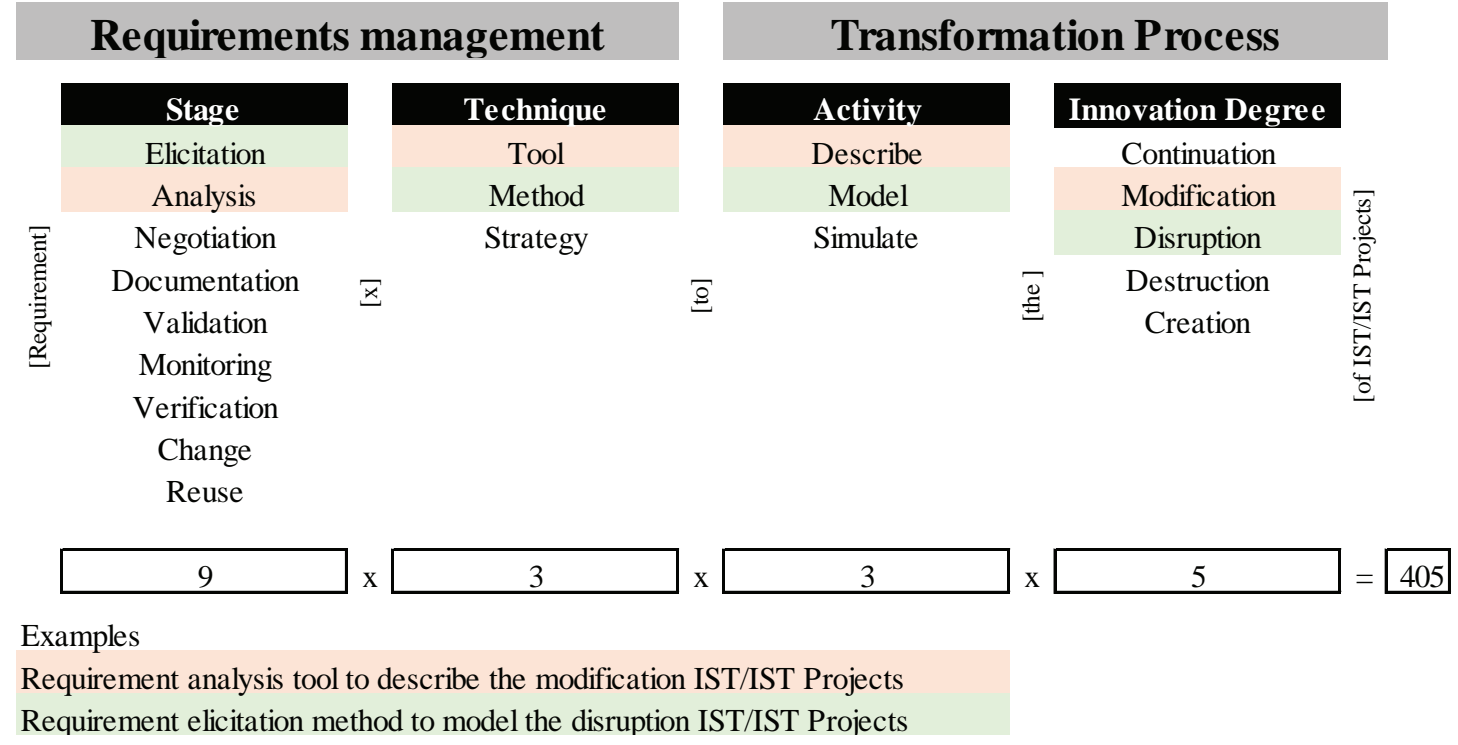

\section{Validating the Ontology}

A mapping procedure of a sample of articles onto the ontology was implemented as a validation process. The results would allow acquiring the sense of how well the ontology performs as a framework, as well as to identify the bright and blind spots of the sample. The latter may support conclusions about what has been done in RE and IST innovations and which areas could be interesting to research in the future and the present empirical study. The validation procedure is explained in the following paragraph and the results and discussed in the next section.

We retrieved the title, abstract and keywords of articles related to the following research queries from the SCOPUS and WoS databases, which contains Spanish and English words for capturing Latin America (LATAM) articles

SCOPUS: (TITLE-ABS-KEY("requirement engineering" OR "requirements engineering" OR "ingenieria de requerimientos" OR "ingeniería de requerimientos”) AND TITLE-ABS-KEY(innovat* OR innov $\left.^{*}\right)$ )

WoS: TODOS LOS CAMPOS: ("requirement engineering" OR "requirements engineering" $O R$ "ingenieria de requerimientos" OR "ingeniería de requerimientos") AND TODOS LOS CAMPOS: (innovat $^{\star}$ OR innov*) Período de tiempo: Todos los años. Índices: SCIEXPANDED, SSCI, A\&HCI, ESCI.
The queries provided a total of 587 records. An analysis of articles related to LATAM, indicated that less than $4 \%$ were related to countries in Latin America (17 from Scopus and 4 from WoS). These results highlight a symptom of the problem related to the small efforts and resources that these countries invest in the innovation, and more specifically, about the relationship between RE and IST projects. Testing the ontology with this dataset does not allows us to obtain robust conclusions, however, the authors decided to use the entire sample in order to validate the ontology and provide future insights for KBoRE for IST innovations, that it could be used by researchers from LATAM as a guide for future investigations.

After obtaining the dataset from the queries, we performed a filtering process, where articles with at least one characteristics of the list below were excluded from the dataset. Implementing this selection, we obtained a total of 525 articles with full information.

1. Absence of title, abstract or keywords (49 records).

2. Duplicate (6).

3. Journal or proceedings conference editorials, letters to the editor or non-peer review documents (7).

The sample of 525 articles included researchers related to RE and Innovation, but not necessarily about transformation in IST projects. For example, in Cleland-Huang, Rahimi, \& Mirakhorli (2015), although RE and Innovation are topics discussed, authors did not study innovation in IST projects. Hence, we performed a heuristic 
analysis for excluding articles whose main purpose and subject are not related to IST innovation projects. Applying the heuristic exclusion process resulted on a final dataset of 212 articles.

Finally, once obtained the final dataset the articles were mapped onto the ontology, using the titles, abstracts and keywords. As it was discussed previously, this mapping process allowed us also to test the internal validity of the taxonomies and the face validity of the ontology, and to identify the bright and blind spots of KBoRE for IST innovations the sample. The mapping was performed by two coders independently, and in order to ensure the use of a same criteria, they first mapped a sample of 20 articles each one, and analyzed the convergence and differences of their coded data. In a first iteration, a convergence index of $60 \%$ was obtained (similarities of the mapping in the ontology). Then coders analyzed the divergences and similarities in the criteria, and discussed about the differences to reach convergence and establish rules for the coding of the rest of the articles in the sample, and to minor modifications to the ontology. Later, they mapped other 20 articles and analyzed the convergence of the second stage. In this iteration, the convergence ratio reached $90 \%$ of agreement in the coding process. Next, the rest of the articles was assigned to the coders and they mapped the articles onto the ontology. The results of the mapping are presented in the following section.

\section{Mapping Results}

According to the mapping, the most covered elements in the sample are the 'elicitation' and 'analysis' stages and 'method' under the Requirements Management subontology. In the Transformation Process subontology, the most documented concepts in the sample are 'describe' in the Activity taxonomy, and 'modification', 'disruption', and 'continuation' in the Innovation Degree. Frequency results are illustrated in Figure 2. Combining the most frequent elements in the ontology, the bright spots in the sample are listed as themes in which the current literature presents models, theories, frameworks, cases or empirical analyses:

* Requirement elicitation method to describe the continuation of IST/IST Projects

* Requirement elicitation method to describe the modification of IST/IST Projects

* Requirement elicitation method to describe the disruption of IST/IST Projects

* Requirement analysis method to describe the continuation of IST/IST Projects

* Requirement analysis method to describe the modification of IST/IST Projects

* Requirement analysis method to describe the disruption of IST/ IST Projects

On the other hand, connecting the less mapped elements from the ontology, the blind spots would be:

${ }^{*}$ Requirement reuse to simulate the destruction of IST/IST Projects

${ }^{*}$ Requirement reuse to simulate the creation of IST/IST Projects

${ }^{*}$ Requirement change to simulate the destruction of IST/IST Projects

${ }^{*}$ Requirement change to simulate the creation of IST/IST Projects
In the four examples of blind spots in the literature, perhaps the less applicable to real life projects are those related to the reuse of requirements for the simulation of destruction (deactivation) of IST projects. However, the simulation of requirement changes and the reuse of requirements for the creation of IST are key unsolved topics in the RE literature and practice, but much needed in the industry of software development and IST project management. The small appearance or the absence of literature about the concepts of change and re-use of requirements, even when these are the most reported issues by IST developers as a source of conflicts with the end users and clients, perpetuates gaps between theory and practice that cost precious resources to IST projects, and in some cases pave the road to failures. Also, there seems to be a fertile field in studying IST simulations of the activity related to digital innovations, as well as negotiation, monitoring and verification of requirements, hence, researchers and practitioners could focus their efforts in identifying if these areas are interesting and relevant for research and then, study new techniques to reduce the knowledge gaps in the discipline, considering the industry's needs for prioritize the innovation in RE. In this vein, some surveys or case-studies could be conducted to identify the industry's needs in this domain. For example, in Chile there is a survey whose objective is identified several technological aspects of companies. This survey is named ENTI (National Study of Information Technology) and allows to collect data by interviewing 152 CIOs. One aspect measured is the Innovation and IT Management, and interesting results are obtained by the analysts, such as that one fifth of the interviewed considered her/his company as an Early Adopter profile and another similar size of group declares their companies invest when IT obsolescence risks are clearly close to capitalize. Plainly the IT Innovation would not be considered as a mature aspect in the Chilean industry, which may not change in the short time due they have not formal process for innovation. The ENTI analysts do not indicate if this companies require for more innovation, however, considering the global trends, these companies will eventually need implement a formal process.

The literature archives researches that indicates learnings and considerations in order to create proper ecosystems for the digitalization transformation process. For example, Villeal et al (2018), provide an extensive analysis of RE in the era of Digital Transformation by framing the review in a set of six domains to get the Ubiquitous RE (RE everywhere, RE with everyone, RE for everything, Automated RE, Open RE, Cross-domain RE). Their analysis identified the importance of taking down barriers and accepting the openness of the software ecosystem that engineers may confront. Also, they indicated the relevance of inventing in requirements and making assumptions for dealing with openness and provide five important lessons: (1) reduce the cycle to test assumptions and requirements, (2) implement an end-to-end thinking of ecosystem business, (3) consider at the same time the business, technical, and legal perspective, (4) align the business model operators and partners platform, and (5) ship platform versions fast in order to learn from stakeholders. Scilicet, researcher and practitioner may identify the bright/blink side in the literature and develop solutions based on RE approach for facilitate the IST innovations in the Digital Transformation required by organizations. 
Figure 2. Frequency of the mapped proceedings onto the KBoRE for IST innovations Ontology.

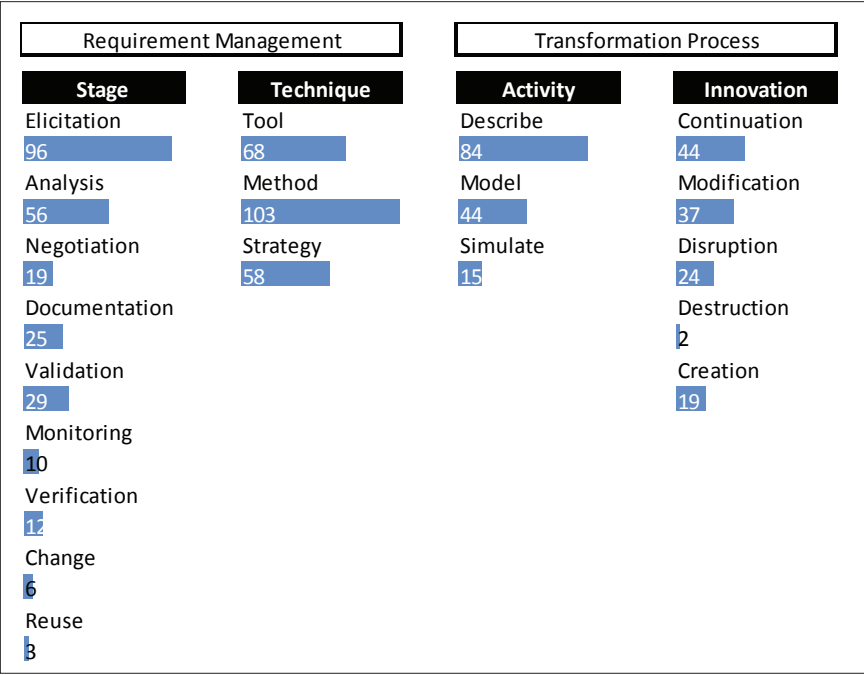

Other type of analysis is related to dyads, where we identified pairs of elements mapped together in the articles. We provide in Figure 3 a matrix and the frequency of articles that include the two topics according the mapping done by the coders. The results illustrated that elicitation-method (44), the method to describe (38), elicitation to describe (33), elicitation tool (32), analysis method (26), tool to describe (25), method to model (25), and describe the continuation (24) are the most common pairs of elements studied in the sample. In second order, the pairs elicitation-analysis, method-strategy, tool-method, method-continuation, method-modification, elicitation-continuation, and analysis-model received so far moderated attention. Also, it is interesting to further analyze the pairs of concepts with a very low frequency or virtual absence of articles associated to them presented here as blind areas and a first point of interest to consider the development of solutions based for example, on artificial intelligence, business process management and machine learning tools.

Figure 3. Paired appearance of elements in the KBoRE for IST innovations Ontology.

\begin{tabular}{|c|c|c|c|c|c|c|c|c|c|c|c|c|c|c|c|c|c|c|c|c|c|}
\hline & \multicolumn{9}{|c|}{ Stage } & \multicolumn{3}{|c|}{ Technique } & \multicolumn{3}{|c|}{ Activity } & \multicolumn{5}{|c|}{ Innovation } \\
\hline & & 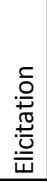 & $\begin{array}{l}\frac{n}{\sqrt{n}} \\
\frac{\pi}{\sigma} \\
\frac{c}{4}\end{array}$ & 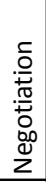 & 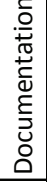 & $\begin{array}{l}\frac{.}{0} \\
\frac{0}{7} \\
\frac{\pi}{0} \\
\frac{.0}{\pi} \\
>\end{array}$ & 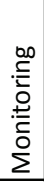 & 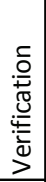 & 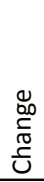 & 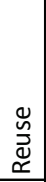 & $\begin{array}{l}\bar{\circ} \\
\circ\end{array}$ & 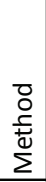 & 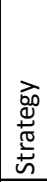 & 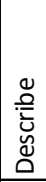 & $\begin{array}{l}\overline{0} \\
\frac{0}{0} \\
\Sigma\end{array}$ & 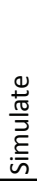 & 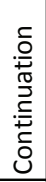 & 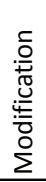 & 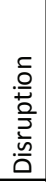 & 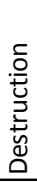 & 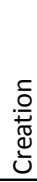 \\
\hline \multirow{9}{*}{ Stage } & Elicitation & & & & & & & & & & & & & & & & & & & & \\
\hline & Analysis & 22 & & & & & & & & & & & & & & & & & & & \\
\hline & Negotiation & 6 & 6 & & & & & & & & & & & & & & & & & & \\
\hline & Documentation & 14 & 5 & 2 & & & & & & & & & & & & & & & & & \\
\hline & Validation & 11 & 7 & 2 & 5 & & & & & & & & & & & & & & & & \\
\hline & Monitoring & 3 & 2 & 1 & 1 & 2 & & & & & & & & & & & & & & & \\
\hline & Verification & 6 & 2 & 2 & 2 & 4 & 2 & & & & & & & & & & & & & & \\
\hline & Change & 2 & 0 & 0 & 0 & 0 & 1 & 1 & & & & & & & & & & & & & \\
\hline & Reuse & 0 & 0 & 0 & 0 & 0 & 0 & 0 & 0 & & & & & & & & & & & & \\
\hline \multirow{3}{*}{ Technique } & Tool & 32 & 17 & 8 & 10 & 11 & 3 & 3 & 0 & 0 & & & & & & & & & & & \\
\hline & Method & 44 & 26 & 9 & 10 & 15 & 5 & 8 & 1 & 2 & 17 & & & & & & & & & & \\
\hline & Strategy & 21 & 17 & 2 & 6 & 7 & 1 & 3 & 2 & 0 & 7 & 19 & & & & & & & & & \\
\hline \multirow{3}{*}{ Activity } & Describe & 33 & 12 & 5 & 9 & 8 & 5 & 3 & 2 & 1 & 25 & 38 & 21 & & & & & & & & \\
\hline & Model & 14 & 19 & 3 & 2 & 9 & 1 & 4 & 0 & 0 & 8 & 25 & 12 & 3 & & & & & & & \\
\hline & Simulate & 6 & 6 & 2 & 1 & 3 & 1 & 2 & 0 & 0 & 6 & 6 & 5 & 1 & 1 & & & & & & \\
\hline \multirow{5}{*}{ Innovation } & Continuation & 19 & 10 & 1 & 7 & 3 & 2 & 4 & 3 & 0 & 14 & 17 & 18 & 24 & 10 & 2 & & & & & \\
\hline & Modification & 14 & 11 & 2 & 2 & 5 & 2 & 2 & 1 & 0 & 10 & 17 & 9 & 19 & 7 & 1 & 10 & & & & \\
\hline & Disruption & 5 & 7 & 1 & 0 & 5 & 1 & 0 & 0 & 0 & 4 & 11 & 8 & 10 & 6 & 2 & 0 & 4 & & & \\
\hline & Destruction & 1 & 0 & 0 & 0 & 1 & 0 & 1 & 0 & 0 & 0 & 1 & 1 & 1 & 0 & 1 & 0 & 1 & 1 & & \\
\hline & Creation & 8 & 7 & 0 & 0 & 2 & 0 & 0 & 0 & 0 & 5 & 8 & 7 & 4 & 9 & 1 & 1 & 0 & 5 & 0 & \\
\hline
\end{tabular}

\section{Discussion and Conclusion}

The proposed ontology decomposed and then structured the body of knowledge of the RE in relationship with innovation in IST projects, providing a holistic view of the topics and areas included in the discipline of IST innovation. Furthermore, through mapping a sample of articles onto the ontology, it was possible to validate the construction and identify the bright and blind/blink areas of knowledge of the RE and Innovation corpus of the sample. According to the results, the publications documented in the sample obtained from two indexed, SCOPUS and WoS, databases have widely studied the methods of elicitation and analysis of requirements to describe modification, continuation and disruption processes in IST projects. Also, the findings reveal areas with lesser research evidenced in the sample such as change and reuse requirements, and simulation and creative destruction transformations. More topics related to the RE management such as negotiation, monitoring, verification and documentation of requirements during IST innovation processes, although not absent, are relatively understudied and could indicate the need and opportunities to theorize and discover solutions for practical and everyday problems in IST projects not covered yet. 
According with the results, this ontology could be used as an input in order to design a research agenda to strategically fill the gaps in literature and systematically expand the scope and depth of the knowledge available in KBoRE for IST innovation. Moreover, for future research, although we lightly contrasted the identified gaps in the literature with some Latin American industry's needs, such the Chilean one, a deeper research on the whole zone is desired in order to prioritize what blind areas of the KBoRE must be according to a, for example, roadmap. Also, mapping a wider sample could robust the conclusions and identify new approaches for those RE techniques with the potential to impact IST innovations and reduce their failure rates and currently high risk. Finally, authors claim for the need of studies about RE in IST innovations in LATAM contexts, since, according to the results from queries, less than $4 \%$ of articles were related to Latin America countries.

\section{References}

Ambreen, T., Ikram, N., Usman, M., \& Niazi, M. (2018). Empirical research in requirements engineering: trends and opportunities. Requirements Engineering, 23(1), 63-95. https://doi.org/10.1007/s00766-016-0258-2

Cancino, C. A., La Paz, A. I., Ramaprasad, A., \& Syn, T. (2018). Technological innovation for sustainable growth: An ontological perspective. Journal of Cleaner Production, 179, 31-41. https://doi. org/10.1016/j.jclepro.2018.01.059

Cheng, B. H., \& Atlee, J. M. (2007, May). Research directions in requirements engineering. In 2007 Future of Software Engineering (pp. 285303). IEEE Computer Society. https://doi.org/10.1109/fose.2007.17

Cleland-Huang, J., Rahimi, M., \& Mirakhorli, M. (2015). Ready-SetTransfer! Technology transfer in the requirements engineering domain. 2015 IEEE 23rd International Requirements Engineering Conference (RE), 412-413. https://doi.org/10.1109/RE.2015.7320461

Coronado, F., La Paz, A., Ramaprasad, A., \& Syn, T. (2015). Navigating the complexity and uncertainty of higher education systems: Ontology mapping of Chile's universities. HERDSA, Learning for Life and World in a Complex World, Australia. ISBN 978-0-908557-96-7

Daneva, M., Damian, D., Marchetto, A., \& Pastor, O. (2014). Empirical research methodologies and studies in Requirements Engineering: How far did we come? Journal of systems and software, 95(12), 1-9. https://doi.org/10.1016/j.jss.2014.06.035

Edquist, C. (1996). Systems of innovation approaches: their emergence and characteristics. Univ. https://doi.org/10.1093/oxford$\mathrm{hb} / 9780199286805.003 .0007$

Geldes, C., Felzensztein, C., \& Palacios-Fenech, J. (2017). Technological and non-technological innovations, performance and propensity to innovate across industries: The case of an emerging economy. Industrial Marketing Management, 61, 55-66. https://doi.org/10.1016/j. indmarman.2016.10.010
Guarino, N., Oberle, D., \& Staab, S. (2009). What Is an Ontology? In S. Staab \& S. R. (Series Ed.), Handbook on Ontologies. https://doi. org/10.1007/978-3-540-92673-3_0

Gunday, G., Ulusoy, G., Kilic, K., \& Alpkan, L. (2011). Effects of innovation types on firm performance. International Journal of Production Economics, 133(2), 662-676. https://doi.org/10.1016/j.ijpe.2011.05.014

Heredia Pérez, J. A., Geldes, C., Kunc, M. H., \& Flores, A. (2019). New approach to the innovation process in emerging economies: The manufacturing sector case in Chile and Peru. Technovation, 79, 35-55. https://doi.org/10.1016/j.technovation.2018.02.012

Kauppinen, M., Savolainen, J., \& Mannisto, T. (2007). Requirements Engineering as a Driver for Innovations. 15th IEEE International Requirements Engineering Conference (RE 2007), 15-20. https://doi. org/10.1109/RE.2007.47

La Paz, A., \& Arrúa, K. 2019. Mapa de las Aspiraciones de la Educación Superior en Paraguay. Revista del CLAD Reforma y Democracia, 74(Junio). ISSN 1314-2378

La Paz, A., Merigó, J. M., Powell, P., Ramaprasad, A., \& Syn, T. 2019. Twenty-five years of the Information Systems Journal: A bibliometric and ontological overview. Information Systems Journal: 27. https:// doi.org/10.1111/isj.12260

La Paz, A. I., Ramaprasad, A., Syn, T., \& Vasquez, J. (2015). An Ontology of E-Commerce - Mapping a Relevant Corpus of Knowledge. Journal of Theoretical and Applied Electronic Commerce Research, 10(2), i-ix. https://doi.org/10.4067/S0718-18762015000200001

Matyokurehwa, K., Mavetera, N., \& Jokonya, O. (2017). Requirements Engineering Techniques: A Systematic Literature Review. International Journal of Soft Computing and Engineering, 7 (1), 14-20. https://doi.org/1https://0.23956/ijarcsse/v6i9/01917

Manzano, C. A., Ramaprasad, A., \& Syn, T. (2018). Information Systems to Manage Local Climate Change Effects: A Unified Framework. PACIS 2018 Proceedings. 11. https://aisel.aisnet.org/pacis2018/11 ISBN: 978-4-902590-83-8

Moira, A. (2016, July). How to pick the best requirements management tool. Retrieved March 27, 2019, from CIO Magazine website: https://www.cio.com/article/3053082/how-to-pick-the-best-requirements-management-tool.html

Munir, H., Wnuk, K., \& Runeson, P. (2016). Open innovation in software engineering: a systematic mapping study. Empirical Software Engineering, 21(2), 684-723. https://doi.org/10.1007/s10664-015-9380-X

Núñez, A., Neriz, L., Mateo, R., Ramis, F., \& Ramaprasad, A. (2018). Emergency departments key performance indicators: A unified framework and its practice. The International Journal of Health Planning and Management, 33(4), 915-933. https://doi.org/10.1002/hpm.2548 
Nuseibeh, B., \& Easterbrook, S. (2000). Requirements engineering: a roadmap. Proceedings of the Conference on The Future of Software Engineering - ICSE '00, 35-46. https://doi.org/10.1145/336512.336523

Oke, A. (2007). Innovation types and innovation management practices in service companies. International Journal of Operations \& Production Management, 27(6), 564-587. https://doi. org/10.1108/01443570710750268

Parnas, D. L. (1999). Software Engineering Programs Are Not Computer Science Programs. IEEE Softw., 16(6), 19-30. https://doi. org/10.1109/52.805469

Porter, M. E. (1998). Clusters and the new economics of competition (Vol. 76). Boston, MA: Harvard Business Scholl Press.

Pyka, A. (2002). Innovation networks in economics: from the incentive-based to the knowledge-based approaches. European Journal of Innovation Management, 5(3), 152-163. https://doi. org/10.1108/14601060210436727

Ramaprasad, A., \& Syn, T. (2015). Ontological Meta-Analysis and Synthesis. Communications of the Association for Information Systems, 37(1). https://doi.org/10.17705/1CAIS.03707

Ramaprasad, A., Win, K. T., Syn, T., Beydoun, G., \& Dawson, L. (2016). Australia's National Health Programs: An Ontological Mapping. Australasian Journal of Information Systems, 20. https://doi. org/10.3127/ajis.v20i0.1335
Robertson, J., \& Robertson, S. (2000). Volere requirements specification template. Atlantic System Guild www.systemguild.com.

Ruhe, G., Nayebi, M., \& Ebert, C. (2017). The vision: Requirements engineering in society. In 2017 IEEE 25th International Requirements Engineering Conference (RE), 478-479. IEEE. https://doi.org/10.1109/ re. 2017.70

Subramanian, A., \& Nilakanta, S. (1996). Organizational innovativeness: Exploring the relationship between organizational determinants of innovation, types of innovations, and measures of organizational performance. Omega, 24(6), 631-647. https://doi.org/10.1016/S03050483(96)00031-X

Villela, K., Hess, A., Koch, M., Falcao, R., Groen, E. C., Dorr, J., ... Ebert, A. (2018). Towards Ubiquitous RE: A Perspective on Requirements Engineering in the Era of Digital Transformation. 2018 IEEE 26th International Requirements Engineering Conference (RE). https://doi.org/10.1109/re.2018.00029

Yaco, S., \& Ramaprasad, A. (2018). Cultural Heritage Semiotics. In Digitisation of Culture: Namibian and International Perspectives. https://doi.org/10.1007/978-981-10-7697-8_4

Zamudio, L., Aguilar, J. A., Tripp, C., \& Misra, S. (2017, July). A Requirements Engineering Techniques Review in Agile Software Development Methods. In International Conference on Computational Science and Its Applications (pp. 683-698). Springer, Cham. https:// doi.org/10.1007/978-3-319-62404-4_50 